\title{
12 Are there institutionalized pathways to the Nobel Prize in economics? 1
}

\author{
Philipp Korom
}

\section{Academic excellence and "power through ideas"}

Throughout most of the 19th century, the academy had been a parochial world subordinated to the will of locally established churches and politicians. Professors did not aim to produce new knowledge but rather to bring forth men who were sociable and cultivated (McClelland, 1980). What Jencks and Riesman (1968) termed an "academic revolution" - by which they meant the triumph of professors and their norms of meritocracy over boards of trustees composed of non-academics and special interest groups - is essentially a recent development. Publications and recognition from those who are qualified to judge slowly emerged as the prime indicator of scholarly achievement in a growing type of academic institution, the "research university" (Menand et al., 2017), in which the professionalization of scholars takes place. ${ }^{2}$

Today all academic disciplines, including economics, have an elaborate system of awards to recognize academic excellence, mostly with a single ne plus ultra award. The best-known awards are the Field Medal in mathematics and the Nobel Prize. Because the Nobel Prize is regarded by laypeople and scientists alike as the acme of scientific achievement, the award gives economists the authority to speak on behalf of science (Lebaron, 2006). However, Laureates themselves have criticized the special standing of the Nobel Prize. Friedrich Hayek, the 1974 Nobel Laureate in economics, feared that the prize could create an aura of hard science certainty around the decidedly social science of economics. ${ }^{3}$ Milton Friedman, the 1976 Nobel Laureate, was skeptical about the assumed universality of Laureates' elite expertise: "I myself have been asked my opinion on everything from a cure for the common cold to the market value of a letter signed by John F. Kennedy."

Outside the field of economics, fervent critiques of the prize have charged that the Nobel Prize system does not recognize the unity of the social sciences in theory and in application (Horowitz, 1983). Given research that consistently demonstrates that economists are less likely to contribute to the public good, others argue that the prize stands in direct contradiction to the founder's will, which stipulated that awards should be given to those who have "conferred the greatest benefit on mankind" (Rothstein, 2015). 
However, despite all these reservations, the Nobel Prize in economics has lost neither its extraordinary visibility nor its prestige. The prize continuously gives discursive power to Nobel Laureates to effectively advance ideas in academics, politics, economics and the media (Maesse, 2015). To give just a few illustrations of the Laureates' impact on the circulation of powerful ideas: Gary S. Becker popularized the notion of "human capital"; Chile implemented an economic recovery plan based on Milton Friedman's policy recommendations in the 1970s; Daniel Kahneman (along with Amos Tversky) changed the way the world thinks about economics, upending the notion that human beings are rational decision-makers; Paul Krugman has become one of the most influential public intellectuals in the social sciences, reaching a wide audience through his columns in the New York Times.

The Nobel Prize does not guarantee lasting esteem by fellow scientists, as "the scientific community is acutely sensitive to signs of its members being 'over the hill'" (Zuckerman, 1977, pp. 238-239). With the emphasis on moving ahead, the prestige of Laureates may turn out to be short-lived as their research is superseded by newer contributions. Yet there seems to be little ebb and flow regarding the scientific legitimacy of Nobel Laureates as public intellectuals. This might also be one of many reasons why key ideas of Laureates easily turn into "public ideas" (Hallett, Stapleton, \& Sauder, 2019) circulating in the news and being used by different mediators (e.g. journalists) for making sense of current events. Examples of such "public ideas" are nudging (R. Thaler), the prize of inequality (J. Stiglitz), the human development index (A. Sen), economic freedom (M. Friedman), and the tragedy of the commons (E. Ostrom).

Given this power of Nobel Laureates in economics to influence the public ("power through ideas," c.f. Carstensen \& Schmidt, 2016), it appears worthwhile to investigate in depth who these scholars actually are. Previous research has categorized Laureates according to their theoretical approaches (Boettke, Fink, \& Smith, 2012; Offer \& Söderberg, 2016, p. 150f.), identified predictors of the Nobel Prize winners in economics (Chan \& Torgler, 2012), analyzed citation trajectories (Bjork, Offer, \& Söderberg, 2014), reconstructed intellectual trajectories through oral history interviews (e.g. Samuelson \& Barnett, 2007), or analyzed the life cycle of scholarly creativity (Weinberg \& Galenson, 2019). What makes this chapter's contribution distinct is its focus on the nexus between academic institutions ${ }^{5}$ and (individual) pathways to achieving the highest level of eminence.

My main argument is that publications in the most prestigious journals, socialization in the top departments of the discipline, and receiving the Nobel Prize produce a circle of interdependencies: Publications in top journals such as the American Economic Review are a precondition for tenure at top departments such as Harvard University (Heckman \& Moktan, 2018). Tenure at prestigious departments then set economists on a trajectory to reach the apex of eminence represented by the Nobel Prize. Finally, Laureates may succeed in further publishing in leading journals, partly because of their reputation. The postulated 


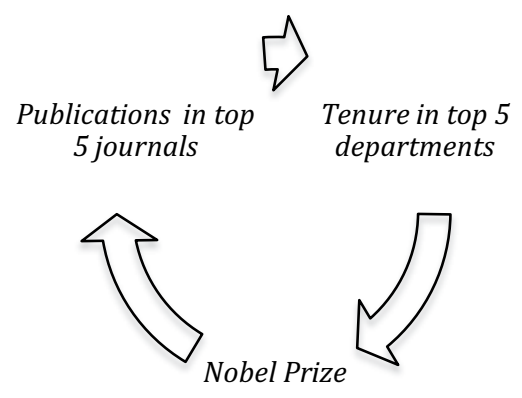

Figure 12.1 Circle of interdependencies

nexus, I will argue, holds true for most but not all cases. The general conclusion is that pathways to eminence in economics are institutionalized and limited.

\section{The prize in economic sciences in memory of Alfred Nobel - a celebration of the power of mind and a political enterprise}

The Nobel Prize is the prize of prizes; no other award carries comparable prestige. The "Sveriges Riksbank Prize in Economic Sciences in Memory of Alfred Nobel" was not mentioned in Alfred Nobel's original testament of 1895 (Nobelstiften, 1972), as were all other Nobel Prizes, but is based on a donation received by the Nobel Foundation in 1968 from Sweden's Central Bank. Its selection procedures were described by Assar Lindbeck, who dominated the prize committee until recently, as follows:

Every October a form, to be filled in which suggested candidates, is sent to professors at about 75 departments of economics all over the world [as well as to previous Laureates] . . . About 150 to 200 proposals are regularly received for the economics prize, usually covering some 75 to 125 nominees . . . After receiving the various proposals, the prize committee commissions expert studies of the most prominent candidates, sometimes by Swedish experts but usually by foreigners . . . The "stock" of candidates that is considered annually hovers around 20-30 persons, though usually only a handful of these are regarded as "hot" names each year . . . The prize is finally decided by simple majority in a secret ballot in this plenary session, where all Swedish members of the [Royal Swedish] Academy [of Sciences] (260 persons) have the right to vote if they participate in the meeting.

(Lindbeck, 1985, pp. 46-47)

Regarding the question of what is considered a prize-worthy contribution, "it is probably correct to say that the selection committee has looked, in particular, 


\section{Philipp Korom}

at the originality of the contribution, its scientific and practical importance, and its impact on scientific work" (Lindbeck, 2001, p. 212). With hindsight, it also becomes apparent that the prize has been awarded for one or several specific contributions (such as the prize for R. C. Merton or M. Friedman) as well as for lifetime contributions (such as the prize for P. Samuelson or S. Kuznets). Between 1969 and 2018, the prize has been awarded 50 times to 81 Laureates.

Despite the rigorous selection procedures and strong links between the award and other indicators of excellence such as citations (Bjork et al., 2014), there is a political undertone to the prize. Offer and Söderberg (2016) argue, based on extensive archival research, that the prize has never escaped the tenuousness of its founding moment. The conflict over "sound money" and government intervention had reached its pinnacle in Sweden. The Central Bank of Sweden attempted to establish its autonomy from politics, which was dominated by Social Democrats, by seizing control over the interest rate ("Åsbrink's interest coup"). The government responded by limiting the degrees of freedom of the bank's governor, Per Åsbrink. To regain credibility, Åsbrink in turn decided to launch a Nobel Prize in economics that could potentially function as a PR campaign for a "market turn" and a change in fundamental attitudes, in which buying and selling between individuals replace social democratic obligations to different social groups.

Empirically, however, Offer and Söderberg find that the award is split roughly evenly between market liberals and economists whose ideas support the principles of social democracy, suggesting that the prize committee is consistently engaged in a delicate balancing act in order to avoid excessive controversy (Offer \& Söderberg, 2016, p. 107f.).

\section{Academic institutions and elite formation}

The prosopographical approach (Charle, 2015) that I adopt here is interested in what people have in common, rather than in how they stand out as individuals. The method allows to gain insight into a group of individuals as a collective by bringing together relevant biographical data. The portrait of the individual is the intermediate aim of prosopographical research while the ultimate purpose is to collect and analyze data on phenomena, such as career line trajectories, that transcend individual lives. In our case study, the descriptive analysis of the sum of biographical data aims at bringing forth communalities between the professional lives of elite economists, which allows insights into how this group of individuals typically navigates professional careers in institutional contexts.

In this chapter, I will specifically investigate whether Nobel Laureates in economics unfold their careers in similar ways by focusing on two types of academic institutions: departments and journals.

Elite departments: Higher education institutions differ in various structural characteristics (e.g. faculty size, admissions selectivity, level of external support) but also regarding the key criteria by which faculty are selected (Musselin, 2010, p. 94f.). Hermanowicz (2005) argues that what sets apart top-tier from 
middle- or low-tier departments is that they place the highest premium on research and recruit only colleagues that aspire to be among the best. Given the widespread obsession in economics with hierarchies of excellence (Fourcade, Ollion, \& Algan, 2015), economists regularly publish rankings of departments. In a recent worldwide ranking of economics departments, Ph.D. education emerges as a highly concentrated activity with the top few departments scoring substantially higher than all others (Amir \& Knauff, 2008). It turns out that the top five (T5) departments are all located in the United States: Harvard University, MIT, Stanford University, Princeton University, and University of Chicago.

Elite journals: Publications in journals are a powerful determinant of eminence in economics (Card \& DellaVigna, 2013). In general, there seems to be a consensus about the so-called top five (T5) journals that can be traced back to an early contribution by Pieters and Baumgartner (2002). If finance journals are set aside, then the $\mathrm{T} 5$ economics journals that publish articles receiving the bulk of attention by the profession are American Economic Review (AER), Econometrica, Journal of Political Economy (JPE), Quarterly Journal of Economics (QJE), and Review of Economic Studies. ${ }^{6}$ Recent research has begun to study the relationship between publications in T5 journals and tenure prospects. Using econometric models, James Heckman and Sidharth Moktan calculated "incest coefficients" indicating the relationship strength between publications in the T5 journals and (tenure-track) employment in the T5 departments of the discipline. Their main finding is that

the JPE has a high incest coefficient $-14.3 \%$ for Chicago affiliates; the non-house-affiliated AER has a relatively high incest coefficient for Harvard faculty who account for $11.9 \%$ of its publication. Most conspicuous is the QJE with a $24.7 \%$ incest coefficient for Harvard affiliates and a $13.9 \%$ coefficient for MIT affiliates.

(Heckman \& Moktan, 2018, pp. 49-50)

Given this cohesive intellectual macrostructure of the discipline, which is clearly dominated by few departments, few journals, and their various interlinkages, it is likely that there are only few elite channels to reach eminence. To probe whether there are few institutionalized pathways ${ }^{7}$ for Nobel Laureates, the following sections will systematically analyze information on the careers and publication behavior of 81 Laureates.

\section{A prosopographical database}

This study is based on a comprehensive biographical database created by the author. Biographical data on 81 Laureates who received the Nobel Prize in economics between 1969 and 2018 were gathered from diverse sources, including official biographies from www.nobelprize.org. However, these biographies rarely contain detailed information on the scholars' time spent in different 


\section{Philipp Korom}

employment positions (or visiting professorships). I have thus relied on the economists' official CVs that are mostly available from their personal webpages. Various editions of the Who's Who in Economics and biographical dictionaries have proved invaluable as well (Blaug, 1999; Breit \& Hirsch, 2009; Vane \& Mulhearn, 2005).

To analyze major career pathways, I use sequence analysis (SA). SA refers to a group of approaches to process longitudinal data representing series of states or events in the life trajectories of individuals. SA includes tools to format sequences, to cluster them, or to represent them in graphical forms (Gauthier, Bühlmann, \& Blanchard, 2014). The SA data file of this case study uses the socalled vertical "time-stamped-event" (TSE) representation that lists the "events" experienced by each scholar along with the time at which the events occurred. Sequences of events can easily be constructed from this representation. As can be seen in Table 12.1, the "events" of interest are full professorships and the "time" is the age at appointment. Additionally, the table lists the name of the department and its prestige rank. Prestige ranks for economics department are taken from Amir and Knauff (2008). The central methodological idea of this ranking is that the "value" of a department is the sum of the "values" of its Ph.D. graduates, as reflected in the "values" of their current employing departments. As departmental prestige may fluctuate over decades, we would ideally like to draw on longitudinal data, which is not available. I will therefore resort to prestige groups (i.e. rank 1-5), thereby treating department ranks simply as orders of magnitude.

An analysis of extended career pathways takes as well into consideration that scholars might leave their home institution temporarily for appointments as a "visiting fellow," or "visiting professor" at another research institution, such as a university or an Institute of Advanced Study (e.g. the CASBS at Stanford University). I decided to consider only stays that lasted at least one full academic semester (4-5 months). ${ }^{8}$ Registering all documented stays for each scholar allows me to construct a dataset with the format outlined in Table 12.2.

Finally, to reconstruct the publication behavior, I used the JSTOR not-forprofit digital library not only to search for publications in journals of a given author, but also to systematically export meta-data of all articles identified. JSTOR assigns research articles to different subjects such as sociology, economics, finance and computer science. I limited the search to the subject category "economics," which includes 181 different journals.

Table 12.1 Snapshot from the sequence data set

\begin{tabular}{llllll}
\hline Timestamp & Prestige rank & Event & Age & ID & Scholar \\
\hline 1978 & rank 11-20 & LSE & 38 & 1 & Akerlof \\
1980 & rank 6-10 & UC-Berkeley & 40 & 1 & Akerlof \\
2014 & rank 21 or lower & U of Georgetown & 74 & 1 & Akerlof \\
$\ldots$ & $\ldots$ & $\ldots$ & $\ldots$ & $\ldots$ & $\ldots$ \\
\hline
\end{tabular}


Table 12.2 Snapshot from the social network dataset

\begin{tabular}{lllll}
\hline Home institution & Host institution & Year & ID & Scholar \\
\hline UC-Berkeley & IAS & 1967 & 1 & Akerlof \\
UC-Berkeley & Indian Statistical Institute & 1983 & 1 & Akerlof \\
$\ldots$ & $\ldots$ & $\ldots$ & $\ldots$ & $\ldots$ \\
\hline
\end{tabular}

\section{Career pathways: Ph.D.-granting departments, professorships, and visiting professorships}

To study the career trajectories of all Nobel Laureates, I build partly on a threestrand model as introduced by Light, Marsden, and Corl (1973, p. 9). These strands are the disciplinary, the institutional, and the external career of faculty, with activities in one strand having implications and consequences for all the other strands.

Disciplinary strand: The first career decision is made within the discipline. Students select their field of study before they choose teaching as a career. It is reasonable to assume that students with a strong research orientation opt for a distinguished Ph.D. program. Besides the doctoral degree, further advancement in the disciplinary strand such memberships in academies are mostly dependent on publication success.

Institutional strand: The primary link between the disciplinary and institutional aspects of faculty careers is the prestige of the Ph.D.-granting department, which is found to be more relevant for obtaining a top position than is the level of productivity during the Ph.D. training (Han, 2003; Long, 1978). I will consider only full professorships, thereby neglecting other stages of a typical institutional career such as chairmanship or early career steps (e.g. associate prof.).

External strand: Finally, academic careers involve many activities outside the major appointment. I will focus on visiting fellowships and professorships of a minimum length of one semester after the Ph.D.

\subsection{Shifts in the geography of obtaining a Ph.D.}

When we look at the Ph.D. institutions of the Nobel Laureates in economics, MIT, Harvard, and U Chicago have clear leading positions ("disciplinary strand"). Altogether, 36 of the 81 Nobel Laureates (44.4\%) obtained a doctorate from a T5 department. If we focus on scholars born in the USA only, then the percentage rises from $44.4 \%$ to $76.6 \%$. This high proportion of Americanborn Laureates with doctorates from $\mathrm{T} 5$ universities suggests that scholars such as Richard H. Thaler, an American Nobel Prize winner who received his Ph.D. from the University of Rochester, are the strict exception.

A network perspective that considers professor-student connections offers a more revealing picture. Tol (2018) reconstructs the (global) professor-student 
network in economics using mostly (but not only) the Academic Family Tree (David \& Hayden, 2012), a collaborative online tool for building an academic genealogy for different disciplines. In the network, which spans five generations with 350 men and 4 women, 72 Nobel Prize winners belong to one single family tree. Instead of studying the entire network, I will focus only on the largest network subcomponent identified by Tol (2018), which starts with one of the leading German economists of the historical school of economics, Karl Gustav A. Knies (1821-1898).

Figure 12.2 shows a directed acyclic graph because in most cases students learn more from their professors than the other way around. The figure reveals, among other things, that George Stigler, James M. Buchanan, and Ronald Coase were students of Frank Knight, and that Robert Lucas was a great-greatgrandstudent of Richard T. Ely. "Master-apprentice relationships" (Heinze, Jappe, \& Pithan, 2019) between two Laureates appear as well frequently in this network (Samuelson-Merton junior, Modigliani-Shiller, Tobin-Phelps). In some cases, the relations identified in Figure 12.2 hint to "schools of thought", which developed around at least one key scholar associated with a paradigm and regarded as a model by several pupils. There exists, for example, a network closeness between the various representatives of the first (e.g. F. Knight) and the second generation (e.g. G. Stigler) of the "Chicago School" (Booth, 1982).

The main insight that can be gained from the subgraph (as from the whole network) is that a Ph.D. from one of the T5 departments was rare in the notso-distant past. Karl Gustav A. Knies and Eugen Böhm von Bawerk (18511914) studied in Germany and Austria. Many of their students (e.g. Joseph Schumpeter, Richard T. Elly), grandstudents (e.g. Allyn A. Young) and greatgrandstudents (e.g. Frank Knight) were academically socialized in the USA but did not receive their Ph.D. from any of the T5 departments. The network perspective thus reveals that while the key place of training for leading economists today are concentrated in $\mathrm{T} 5$ departments, they have been far more variable over time than commonly assumed.

\subsection{Main career pathways}

To depict the diversity of career trajectories ("institutional strand") and track each individual pattern, I will use a decorated parallel coordinate plot as introduced by Bürgin and Ritschard (2014). Such a plot enables us to identify the most typical career patterns while also revealing the diversity within the entire set of observed career trajectories at the same time. Such a visualization further helps us to understand how professorships throughout a scholar's career relate to the prestige ranks of departments.

In Figure 12.3, each line represents a unique, observed order pattern, and the line width reflects the frequency of the pattern. The lines are jittered to avoid overlapping and to help identify typical patterns; only patterns which make up at least $3 \%$ of all 80 considered cases are highlighted in dark grey. ${ }^{9}$ To facilitate the tracking of distinct patterns, there are gray arrangement zones at the 


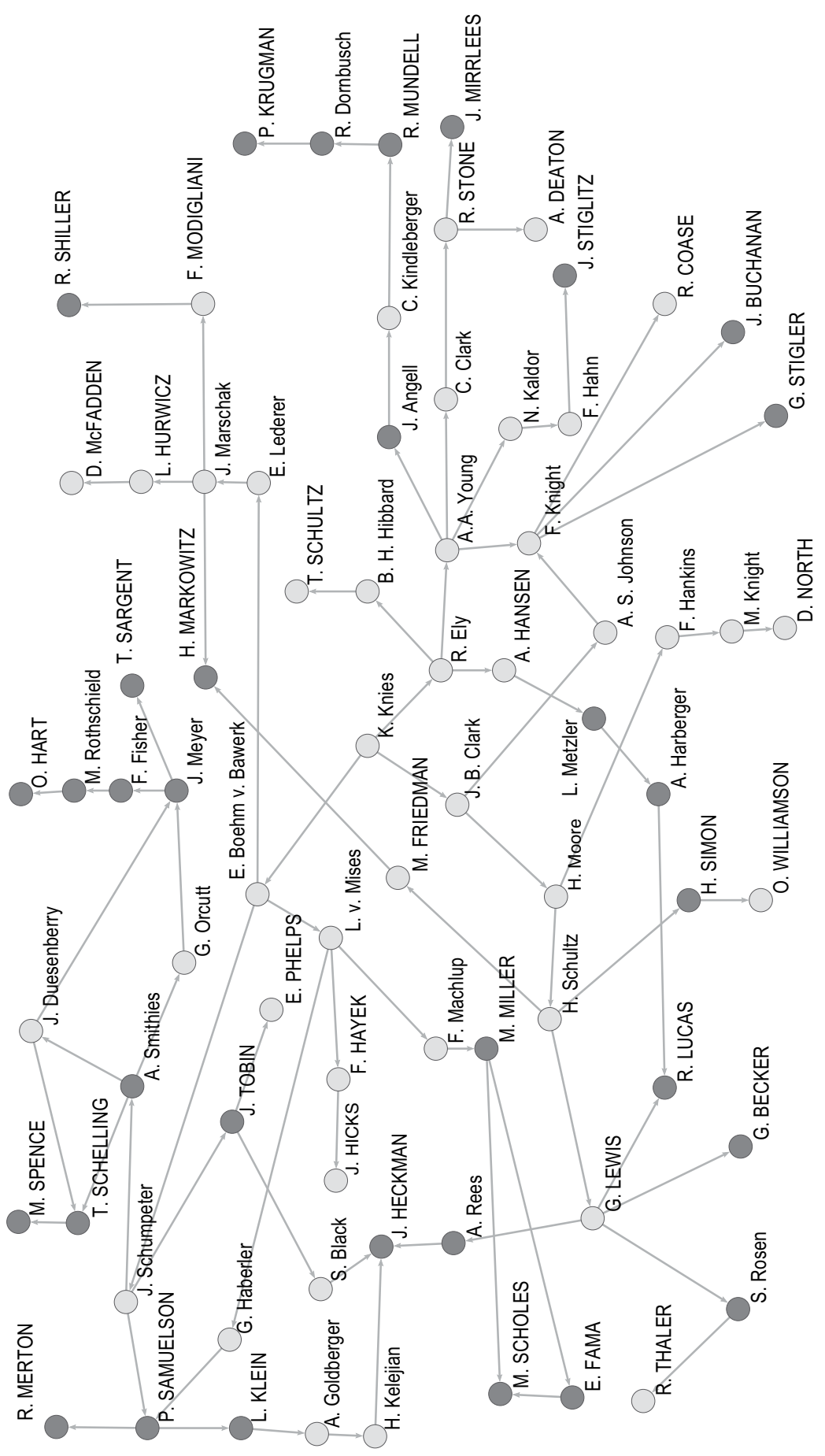

艘 


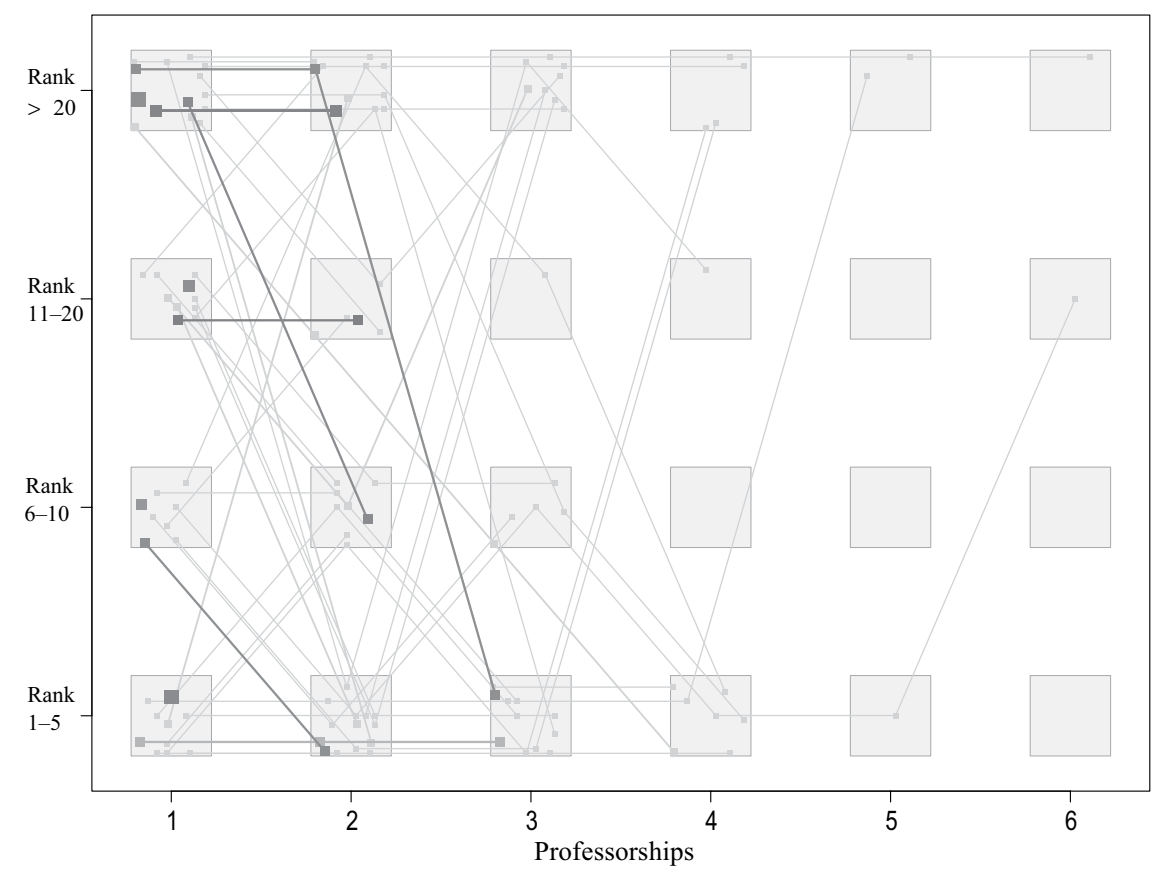

Figure 12.3 Career trajectories clustered by departmental prestige rank groups (Amir \& Knauff, 2008)

intersection of the $x$ coordinate (stage in a scholar's career) and the $y$ coordinate (rank of the department).

Looking at the colored lines in Figure 12.3, we learn that three of the six most frequent patterns lead to T5 departments. We can, for example, derive that a more commonly experienced pattern is to hold at the career beginning two consecutive professorships at departments with ranks below 20 and then be appointed professor at a department with the highest prestige (rank 1-5). The careers of Ronald H. Coase, Arthur W. Lewis, William F. Sharpe, and Alvin E. Roth are marked by such a specific career trajectory, which is highlighted in orange in Figure 12.3. In-house careers are quite widespread as well. Peter A. Diamond, Eugene F. Fama, Milton Friedman, Lars P. Hansen, Merton H. Miller, Paul Samuelson, and Robert M. Solow were all appointed as full professors at one of the T5 departments and did not switch departments. Another striking feature of the most common career paths is that there are very few moves to lower-ranked departments, which are in general rare and only characteristic of the final career steps in the trajectories (professorships 4-6).

Out of the 186 different full professorships considered in the biographical database, $33.9 \%$ were held at T5 departments. Out of the 81 Nobel Laureates considered, 42 held at least one full professorship at one of the T5 departments. 
Many of those who never made it into these elite departments pursued most of their careers outside the USA (e.g. James A. Mirrless, Bertil G. Ohlin, and Reinhard Selten). Combining this aggregate information with the sequential patterns presented in Figure 12.3 allows me to conclude that most Nobel Laureates follow a standardized career path that leads them to the very top in the departmental hierarchy.

\subsection{Visiting networks}

Elite careers are shaped by two distinct forces: hierarchies and networks. Universities are hierarchical structures in which elites quickly move through lower positions (assistant prof., associate prof.) to reach the final career plateau, from which there is nowhere to go professionally within the very same institution. Elites, however, can also entertain multiple affiliations by visiting other research institutions ("external strand"). By doing so, they establish networks between the home institution and other visiting institutions. To obtain a global view of the relatively large visiting network, I decided to shrink all vertices (i.e. home/ visiting institutions) belonging to a certain (prestige) class to one single vertex. For example, I shrank all US departments belonging to the top five ranked departments to a new vertex labeled "USA \{rank 1-5\}." The arcs in Figure 12.4 are unidirectional, indicating the number of scholars moving temporarily from a home institution of a certain class to another class of host institutions. ${ }^{10}$

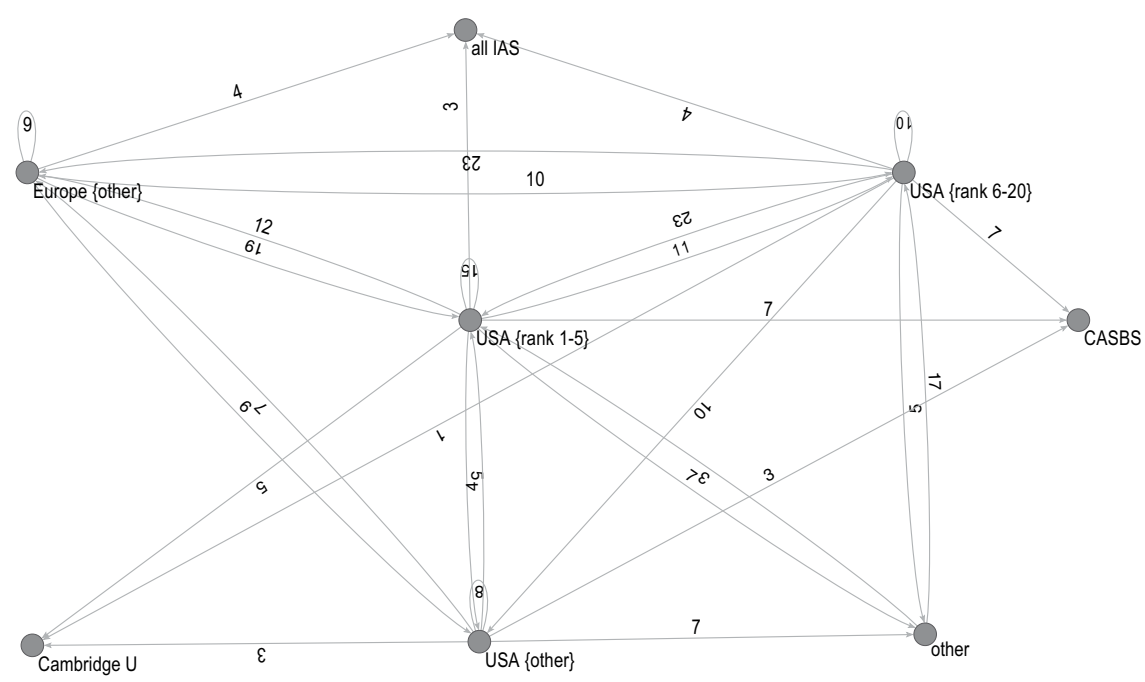

Figure 12.4 Visiting relationships between different types of institutions $(N=130)$

Note: Arcs indicate the direction of the relationship. Considered are only multiple relationships equal to or greater than three. IAS stands for all Institutes of Advanced Studies (except for the Center for Advanced Study in the Behavioral Sciences, CASBS). 
In the "shrunken network," most scholars leave second-tier US departments (rank 6-20) to either visit US top-tier departments (rank 1-5) or to conduct studies at European departments. Moreover, there is a significant inflow from Europe to the top US departments as well as a high circulation between departments belonging to the top five. The overall network structure also suggests that the "big five" are the main magnet in the visiting network, which is confirmed by the "indegree distribution." Although the category "USA (rank 1-5)" encompasses only five institutions, it has an indegree of 65 , while a category such as "USA (rank 6-20)" with 11 departments is marked by a comparatively low indegree of $48 .{ }^{11}$

\section{Publication in top five journals}

In the last step of the analysis, I will investigate whether Nobel Laureates strive not only to work at top departments but also to publish in top journals. There are at least two reasons why we should expect to find Nobel Laureates' publications concentrated in the five leading journals: First, publications in top-notch journals are not only an important measure of visibility but also, at least partly, a rough proxy of the (recognized) excellence of a scholar. Second, and more specifically, there is evidence that publishing in T5 journals has an inbred nature: Editors are likely to select papers of those they know mostly through joint departmental affiliations (Colussi, 2018; Heckman \& Moktan, 2018). That editors of theT5 journals and Nobel Laureates are both likely to be associated with a T5 department should therefore positively affect the chances of publication in T5 journals. Moreover, Heckman and Moktan have found evidence that publications in T5 journals are in general a strong predictor of tenure in T5 departments. It is very likely that this institutional link is also important to understand the careers of Nobel Laureates.

In what follows, I aim to establish empirically whether there is indeed a strong connection between publications in top journals and winning the Nobel Prize. Further, I want to know whether the link grew stronger as the discipline matured. To these ends, Figure 12.5 depicts the number of publications in elite and non-elite journals separately for Laureates belonging to four different age groups.

The major insight gained from Figure 12.5 is that Laureates publish on average every second paper in a T5 journal. In general, T5 publications figure high if one considers that JSTOR allows one to search 181(!) economics journals. Scholars such as Herbert Simon, Kenneth Arrow, and Robert J. Aumann have published nearly exclusively in T5 journals. There are only a few scholars with no publications at all in T5 journals. These scholars have in common that they mostly work in research areas that do not represent mainstream economics. ${ }^{12}$

Further, it becomes apparent that the general pattern does not vary much across age groups, which suggests that the link between publishing in T5 journals and receiving the Nobel Prize is not a recent phenomenon at all. 

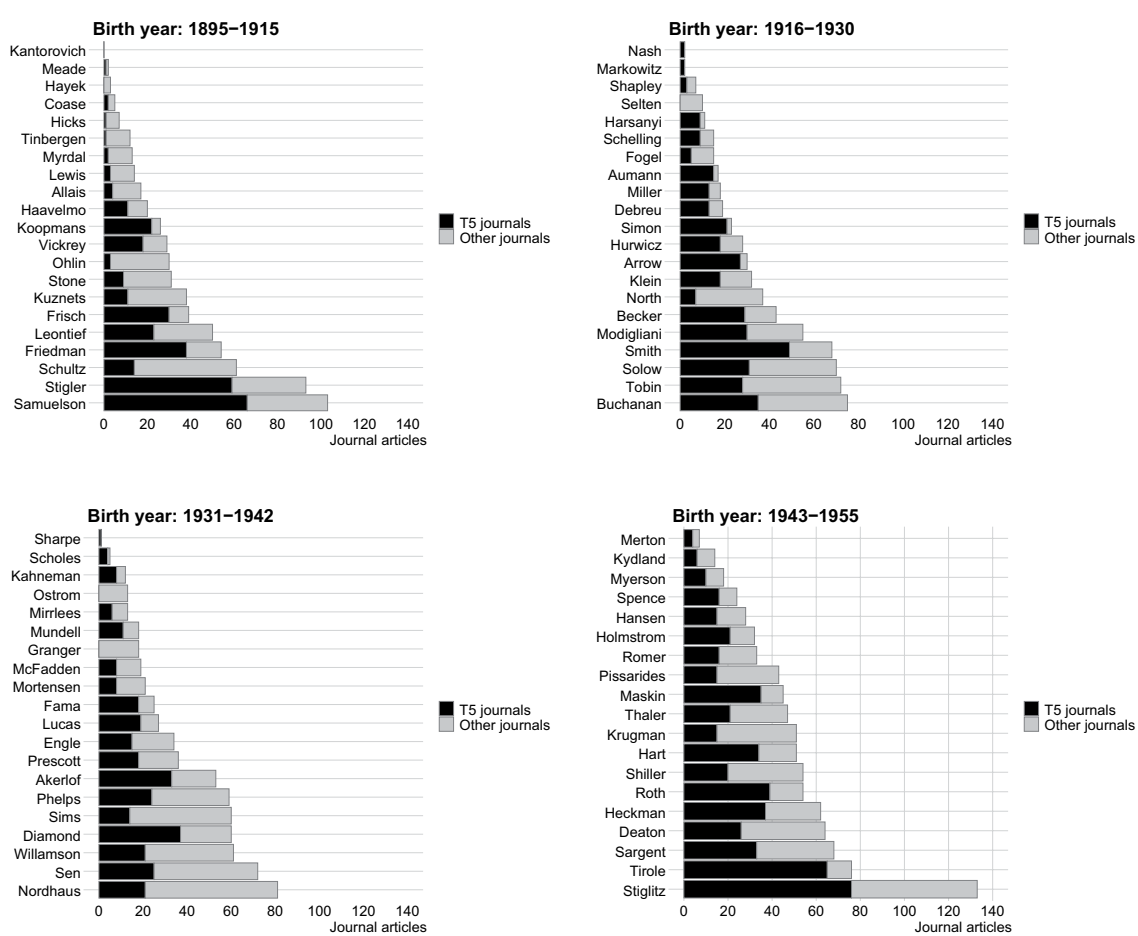

Figure 12.5 Publications in elite and non-elite journals

Nobel Laureates thus appear - much like their fellow economists - to be hyperaware of the top five's ability to make or break their career. To receive a Nobel Prize in economics without any T5 publications is not an unseen phenomenon (see the case of Soviet mathematician and economist Leonid V. Kantorovich), but the dominant route to tenure at a leading economics department or to the Nobel Prize in economics is clearly via publications in T5 journals.

\section{Economics: a hierarchical discipline with homogenous elite careers}

This contribution tried to shed some light on a group of Nobel Laureates in economics whose ideas have significant repercussion in the academic world, and in some cases, outside of it. Kenneth Arrow, for example, helped transform economic theory into a mathematical science, created modern social choice theory, and established most of the major findings in general equilibrium theory (Maskin, 2019). While highly influential in the discipline, the Nobel Laureate Arrow reached less recognition outside the discipline than, for example, Amartya Sen or Paul Krugman (Prinz, 2017). Flip through the past year's issues 
of the New Republic, the New York Review of Books, or the New York Times and you will find many references to these two economists. Others, like Milton Friedman, provided the intellectual foundation for public policies. Friedman's influence on the anti-inflation, tax-cutting, and antigovernment policies of Ronald Reagan or Margaret Thatcher is difficult to overstate (Forder, 2019).

Using prosopographical tools, I have shown that the academic careers of Nobel Laureates in economics have enough in common for connections to be uncovered. More specifically, I have laid bare institutionalized pathways to the Nobel Prize, implying that individuals follow similar routes shaped by the overall intellectual structure of the discipline. This macrostructure is hierarchically organized with five top departments and (their in-house) journals dominating the discipline. While my analysis cannot reveal whether economists pursue some rational "master plan" to win the Nobel Prize, ${ }^{13}$ it becomes apparent that most of them pursue their careers through the same "institutional elite channels": Nobel Laureates in economics are either hired by one of the top five departments, and/or they work towards a visiting professorship at MIT, Harvard, Stanford, Princeton, or University of Chicago. To enter these elite circles, they regularly publish in the T5 journals whose editors are mostly affiliated with one of the T5 departments. Furthermore, I can empirically show that in many cases there exist master-apprentice relationships between Nobel Laureates (that were formed at one of the T5 departments). A prominent example is Kenneth Arrow, who taught at Harvard and Stanford and mentored graduates who became Nobel Laureates themselves: John C. Harsanyi, Eric S. Maskin, Roger B. Myerson, A. Michael Spence, and Joseph E. Stiglitz.

These results point to a relatively homogenous elite that is shaped by an elite subset of American institutions rather than by departments across the United States or the world. The dominance of few departments goes hand in hand with a unitary disciplinary structure. While other social science disciplines like sociology are fractious with many specialties and few interlinkages between them, economics is found to have a "sizeable [intellectual] core that incorporates a number of major subfields" (Crane \& Small, 1992). Mathematical models - commonly recognized as the "golden standard" (Rodrik, 2016) build bridges between specialties and hold economics as a discipline together.

Now, consensus implies control as well. The relationship between disciplinary consensus (of what constitutes good science) and control is, as Fourcade et al. (2015, p. 96) argue, an intricate one:

there might be more consensus because there is more control (for instance if a consistent view of what constitutes quality research is promoted by those who control the top journals); conversely, control might be more effective and enforceable because there is more consensus.

Whatever the case, in the end the unitary and hierarchical structure leads to few pathways to the uppermost levels of prestige in economics, with powerful gatekeepers affiliated with the T5 departments of the discipline. As the Nobel 
committee decided not to stray too far away from the discipline's internal prestige rankings (Offer \& Söderberg, 2016), the majority of all Nobel Laureates reveal similar pathways connected with top departments and top journals.

Finally, it should be noted that my findings - that there are institutionalized pathways to the Nobel Prize in economics - do not allow me to explain why some who were at the pinnacle of economics, such Joan Robinson or John K. Galbraith, did not receive the prize, nor to make reasonable predictions of who will join the group of Laureates in the future. However, the conceptual model for analyzing typical career pathways put forward in this contribution can be put to use in a different way. What can be "tested" is whether a new Laureate fits or deviates from the picture presented in this chapter. Recurrent "fits" tell us that economics has not changed, while recurrent "misfits" hint, most likely, to a de-institutionalization of elite careers that stem from major changes from within the discipline.

\section{Notes}

1 Acknowledgement: This study was financially supported by the Austrian Science Fund (FWF, project number: P29211).

2 Research became the preeminent marker of academic prestige around the end of the 19th century, as reflected in psychologist James McKeen Cattell's (1860-1944) early endeavors to measure scientific eminence. Cattell asked leading representatives of 12 disciplines (e.g. anatomy) to rank the most eminent scientists (e.g. anatomists) in their respective background disciplines by giving priority to the scientists' contributions to research (Cattell, 1906).

3 Friedrich August von Hayek's speech at the Nobel Banquet, December 10, 1974. (www. nobelprize.org/prizes/economic-sciences/1974/hayek/speech/, 5th of July, 2019).

4 Milton Friedman's speech at the Nobel Banquet, December 10, 1976 (www.nobelprize. org/prizes/economic-sciences/1976/friedman/speech/, 5th of July, 2019).

5 Institutions are here understood to be the building blocks of social order representing "collectively enforced expectations with respect to the behavior of specific categories of actors or to the performance of certain activities" (Streeck \& Thelen, 2005, p. 9). In this sense, chairs of elite departments (e.g. Harvard University) must recruit strong faculty members, and editors of top journals (e.g. American Economic Review) are expected to publish cutting-edge research. It is these social pressures that organize the behavior of actors in academia into rather predictable patterns.

6 Editors of all five journals are usually associated with one of the T5 departments. Currently, Esther Duflo (MIT) is the editor of the AER, Joel Sobel (UC San Diego) of Econometrica, Harald Uhlig (University of Chicago) of the JPE, Andrei Shleifer (Harvard University) et al. of the Quarterly Journal of Economics, Jerome Adda (Bocconi University) et al. of the Review of Economic Studies.

7 This compound term is inspired by the concept of the "institutionalized life course" that was first coined by Kohli (1985). It presupposes an institutional pattern that shapes lives both in terms of movement through positions and of biographical plans. The concept is frequently used in the social sciences, as there is an abundance of evidence that individual trajectories are shaped by meso- and macro-level institutional conditions.

8 In some cases, however, it is impossible to know the exact length of stay. The curriculum vitae of Christopher A. Sims, for example, reveals that he was a visiting professor at Yale University in 1974. I can only assume that such information implies that Sims spent at least one semester at Yale (and not less time). 


\section{Philipp Korom}

9 Please note that John Nash could not be included because he is the only Laureate with no full professorship.

10 A visit to a host institution was only counted once per scholar. To give an example: The economist Peter A. Diamond was a visiting fellow at Harvard University twice throughout his career. In the analysis, however, I establish only a single link between MIT (home institution) and Harvard University (host institution) based on this information.

11 In social network analysis the term "indegree" stands for the number of arcs coming into a vertex.

12 Friedrich Hayek, for example, is mostly known for his contributions to the philosophy of science, and Reinhard Selten is considered one of the fathers of experimental economics.

13 The chosen research design does not allow me to investigate scholars' intentions and motives. To understand the "internal mechanism" of the detected institutionalized pathways, qualitative in-depth studies are warranted (see also Becker (2017) on evidence in the social sciences). To most economists the Nobel Prize comes, at least partly, as a surprise (see, for example, Alvin E. Roth's reactions to the prize on YouTube. The YouTube video was uploaded by Stanford University on October 15, 2012, with the title "Stanford Visiting Professor Al Roth Reacts to Winning the 2012 Nobel for Economics").

\section{References}

Amir, R., \& Knauff, M. (2008). Ranking Economics Departments Worldwide on the Basis of PhD Placement. The Review of Economics and Statistics, 90(1), 185-190.

Becker, H. S. (2017). Evidence. Chicago and London: The University of Chicago Press.

Bjork, S., Offer, A., \& Söderberg, G. (2014). Time Series Citation Data: The Nobel Prize in Economics. Scientometrics, 98(1), 185-196.

Blaug, M. (1999). Who's Who in Economics (3rd ed.). Cheltenham and Northampton, MA: Edward Elgar.

Boettke, P. J., Fink, A., \& Smith, D. J. (2012). The Impact of Nobel Prize Winners in Economics: Mainline vs. Mainstream. American Journal of Economics and Sociology, 71(5), 1219-1249.

Booth, W. C. (1982). Between Two Generations: The Heritage of the Chicago School. Profession, 19-26.

Breit, W., \& Hirsch, B. T. (Eds.). (2009). Lives of the Laureates: Twenty-Three Nobel Economists. Cambridge, MA: MIT Press.

Bürgin, R., \& Ritschard, G. (2014). A Decorated Parallel Coordinate Plot for Categorical Longitudinal Data. The American Statistician, 68(2), 98-103.

Card, D., \& DellaVigna, S. (2013). Nine Facts about Top Journals in Economics. Journal of Economic Literature, 51(1), 144-161.

Carstensen, M. B., \& Schmidt, V. A. (2016). Power through, over and in Ideas: Conceptualizing Ideational Power in Discursive Institutionalism. Journal of European Public Policy, 23(3), 318-337.

Cattell, M. J. (1906). American Men of Science: A Biographical Directory. New York: The Science Press.

Chan, H. F., \& Torgler, B. (2012). Econometric Fellows and Nobel Laureates in Economics. Economics Bulletin, 32, 3365-3377.

Charle, C. (2015). Prosopography (Collective Biography). In J. D. Wright (Ed.), International Encyclopedia of the Social and Behavioral Sciences (pp. 256-260). Amsterdam: Elsevier.

Colussi, T. (2018). Social Ties in Academia: A Friend Is a Treasure. The Review of Economics and Statistics, 100(1), 45-50. 
Crane, D., \& Small, H. (1992). American Sociology since the Seventies: The Emerging Identity Crisis in the Discipline. In T. C. Halliday \& M. Janowitz (Eds.), Sociology and its Publics: The Forms and Fates of Disciplinary Organization (pp. 197-234). Chicago: University of Chicago Press.

David, S. V., \& Hayden, B. Y. (2012). Neurotree: A Collaborative, Graphical Database of the Academic Genealogy of Neuroscience. PLoS ONE, 7(10), e46608.

Forder, J. (2019). Milton Friedman. New York: Springer.

Fourcade, M., Ollion, E., \& Algan, Y. (2015). The Superiority of Economists. Journal of Economic Perspectives, 29(1), 89-114.

Gauthier, J.-A., Bühlmann, F., \& Blanchard, P. (2014). Introduction: Sequence Analysis in 2014. In P. Blanchard, F. Bühlmann, \& J.-A. Gauthier (Eds.), Advances in Sequence Analysis: Theory, Methods, Applications (pp. 1-17). New York: Springer.

Hallett, T., Stapleton, O., \& Sauder, M. (2019). Public Ideas: Their Varieties and Careers. American Sociological Review, 84(3), 545-576.

Han, S.-K. (2003). Tribal Regimes in Academia: A Comparative Analysis of Market Structure across Disciplines. Social Networks, 25(3), 251-280.

Heckman, J. J., \& Moktan, S. (2018). Publishing and Promotion in Economics: The Tyranny of the Top Five. INET Working Papers, No. 82.

Heinze, T., Jappe, A., \& Pithan, D. (2019). From North American Hegemony to Global Competition for Scientific Leadership? Insights from the Nobel Population. PLOS ONE, 14(4), e0213916.

Hermanowicz, J. C. (2005). Classifying Universities and Their Departments: A Social World Perspective. The Journal of Higher Education, 76, 26-55.

Horowitz, I. L. (1983). Toward a Nobel Prize for the Social Sciences. PS: Political Science \& Politics, 16(1), 57-58.

Jencks, C., \& Riesman, D. (1968). The Academic Revolution. Garden City, NY: Doubleday \& Co.

Kohli, M. (1985). The Institutionalization of the Life Course: Historical Findings and Theoretical Arguments. Kölner Zeitschrift Für Soziologie Und Sozialpsychologie, 37(1), 1-29.

Lebaron, F. (2006). "Nobel” Economists as Public Intellectuals: The Circulation of Symbolic Capital. International Journal of Contemporary Sociology, 43(1), 88-101.

Light, D. W., Maresden, L. R., \& Corl, T. C. (1973). The Impact of the Academic Revolution on Faculty Careers. Washington, DC: ERIC Clearinghouse on Higher Education.

Lindbeck, A. (1985). The Prize in Economic Science in Memory of Alfred Nobel. Journal of Economic Literature, 23(1), 37-56.

Lindbeck, A. (2001). The Sveriges Riksbank (Bank of Sweden) Prize in Economic Science in Memory of Alfred Nobel 1969-2000. In A. W. Levinovitz \& N. Ringertz (Eds.), The Nobel Prize. The First 100 Years (pp. 197-217). London and Singapore: Imperial College Press and World Scientific Publishing.

Long, J. S. (1978). Productivity and Academic Position in the Scientific Career. American Sociological Review, 43(6), 889-908.

Maesse, J. (2015). Economic Experts: A Discursive Political Economy of Economics. Journal of Multicultural Discourses, 10(3), 279-305.

Maskin, E. S. (2019). The Economics of Kenneth J. Arrow: A Selective Review. Annual Review of Economics, 11, 1-26.

McClelland, C. E. (1980). State, Society and University in Germany 1700-1914. Cambridge: Cambridge University Press.

Menand, L., Reitter, P., \& Wellmon, C. (2017). The Rise of the Research University. Chicago: The University of Chicago Press. 


\section{Philipp Korom}

Musselin, C. (2010). The Market for Academics. New York: Routledge.

Nobelstiften (1972). Nobel: The Man and his Prizes. New York: American Elsevier.

Offer, A., \& Söderberg, G. (2016). The Nobel Factor: The Prize in Economics, Social Democracy, and the Market Turn. Princeton, NJ: Princeton University Press.

Pieters, R., \& Baumgartner, H. (2002). Who Talks to Whom? Intra- and Interdisciplinary Communication of Economics Journals. Journal of Economic Literature, 40(2), 483-509.

Prinz, A. (2017). Memorability of Nobel Prize Laureates in Economics. Applied Economics Letters, 24(6), 433-437.

Rodrik, D. (2016). Economics Rules: The Rights and Wrongs of the Dismal Science. New York: Norton.

Rothstein, B. (2015, October 11). Ekonomipriset i strid med andan i Nobels testamente. Dagens Nyheter.

Samuelson, P. A., \& Barnett, W. A. (Eds.). (2007). Inside the Economist's Mind: Conversations with Eminent Economists. Malden, MA: Blackwell.

Streeck, W., \& Thelen, K. A. (Eds.). (2005). Introduction: Institutional Change in Advanced Political Economies. In Beyond Continuity: Institutional Change in Advanced Political Economies (pp. 1-39). Oxford ; New York: Oxford University Press.

Tol, R. S. J. (2018). Rise of the Kniesians: The Professor-student Network of Nobel Laureates in Economics. University of Sussex Working Paper, No. 05.

Vane, H. R., \& Mulhearn, C. (2005). The Nobel Memorial Laureates in Economics: An Introduction to their Careers and Main Published Works. Cheltenham: Elgar.

Weinberg, B. A., \& Galenson, D. W. (2019). Creative Careers: The Life Cycles of Nobel Laureates in Economics. De Economist. https://doi.org/10.1007/s10645-019-09339-9

Zuckerman, H. (1977). Scientific Elite: Nobel Laureates in the United States. New York: Free Press. 